\title{
Atividades de ensino e interação entre pares: favorecendo o desenvolvimento de competencias discursiwas em LE
}

\author{
Teaching activities and classroom interaction: fostering the \\ development of foreign language communicative competences
}

\author{
Rita de Cássia Gomes ${ }^{1}$ \\ Universidade Federal de Viçosa- UFV
}

DOI: https://doi.org/10.5902/2176148538709

Resumo: Levar os aprendizes a falar no idioma estrangeiro constitui umas das missões do docente de línguas e, ao mesmo tempo, uma orientação das metodologias de ensino em voga atualmente. Sendo assim, refletir acerca das ferramentas a serem utilizadas para alcançar esse feito torna-se fundamental, sobretudo em contextos em que a fala na língua estrangeira é restrita à sala de aula. No presente artigo apresento, com base em obras relacionadas à questão, as contribuições de um ensino em que é favorecida a interação entre pares por meio de atividades didáticas que propiciem o desenvolvimento de competências para se comunicar em LE.

Palavras-chave: Atividades didáticas. Produção oral. Interação entre pares.

Abstract: Guiding learners to speak a foreign language is one of the missions of language teacher. It is likewise an important guideline to the current teaching methodologies. Therefore, it has become fundamental to reflect on the tools that can be used to achieve that goal, especially when, due to the context, speaking in the target foreign language is restricted to the classroom. On this paper, based on the literature concerning this topic, we present the contribution of a teaching experience in which we favor classroom interaction through didactic activities that foster the development of foreign language communicative competences.

Keywords: Didactic activities. Oral production. Classroom interaction.

1 Professora de Língua Francesa na Universidade Federal de Viçosa. Doutoranda no Programa de Letras Estrangeiras e Tradução do Departamento de Letras Modernas da Faculdade de Filosofia, Letras e Ciências Humanas da Universidade de São Paulo. 


\section{Introdução}

As reflexões apresentadas no presente artigo estão intimamente relacionadas à minha pesquisa de doutorado, a qual está em andamento no Programa de Letras Estrangeiras e Tradução da FFLCH-USP. Uma das hipóteses da pesquisa é a de que, ao proceder à elaboração de atividades didáticas cujo objetivo seja (ou deveria ser) proporcionar aos alunos o desenvolvimento de habilidades para interagir oralmente na língua-alvo, o professor deve favorecer, por meio dessas atividades, o contato entre os aprendizes, permitindo que realizem oralmente a tarefa

Rita de Cássia Gomes proposta de forma conjunta. Tal postura pedagógica permitirá que os aprendizes procedam, dessa forma, à intercompreensão, interlocução ou coprodução discursiva, objetivo de toda interação verbal face a face.

0 trabalho relacionado à oralidade no ensino de uma língua estrangeira (LE) é um tema que me interessa há bastante tempo, tanto no que diz respeito ao meu papel enquanto docente quanto no que tange ao meu percurso enquanto pesquisadora. Em minha dissertação de mestrado, dediquei-me a verificar se seria possível proporcionar interações que colocassem os aprendizes em situação de coprodução discursiva desde os primeiros contatos com a língua-alvo. A prática docente foi o que motivou meu percurso enquanto pesquisadora, pois, por acreditar que é fundamental proporcionar um ensino que leve os aprendizes a falar no idioma estrangeiro desde o início da aprendizagem, enveredei pelos caminhos da pesquisa, no intuito de investigar como e se seria possível realizar tal feito.

Sendo assim, em minha pesquisa de mestrado ofereci um curso experimental, durante o qual algumas interações (face a face) foram registradas e vieram a constituir o corpus da pesquisa. Essas interações ocorreram sem preparação prévia por parte dos aprendizes e foram propostas de forma progressiva, respeitando os objetivos linguístico-comunicativos apresentados pelo livro didático adotado pelo curso em que a pesquisa foi realizada ${ }^{2}$. Com o objetivo de verificar se os alunos conseguiram se comunicar, respeitando as regras de uma interação verbal face a face, procedi à análise das transcrições, tomando por base, sobretudo, os estudos de Kerbrat-Orecchioni (1990) e Marcuschi (2008).

2 O curso experimental de francês para iniciantes ocorreu nos meses de fevereiro e julho de 2011, junto aos Cursos Extracurriculares de Francês oferecidos pelo Serviço de Cultura e Extensão da Faculdade de Filosofia, Letras e Ciências Humanas da Universidade de São Paulo. Tratou-se, portanto, de um curso intensivo com duração de quatro semanas e cuja carga horária foi de 45 horas. Adotamos o material didático Alter Ego 1 (editora Hachette), conforme ocorria nos demais cursos de francês oferecidos pelos Cursos Extracurriculares. 
Os dados analisados evidenciaram que os aprendizes alcançaram as metas comunicativas visadas pelas propostas de interação, recorrendo a estratégias de diversas ordens para assegurar a intercompreensão e, consequentemente, a realização da situação proposta pela atividade.

Finalizada a dissertação de mestrado, outras questões vieram a me inquietar enquanto pesquisadora. Minha atenção na pesquisa de mestrado estava voltada para os aprendizes, para a possibilidade de haver ou não comunicação efetiva no início da aprendizagem. Faltaram, entretanto, dois aspectos a serem analisados, os quais, dados o fator tempo e os objetivos daquela pesquisa, não tiveram como ser investigados. Trata-se do instrumento que deu origem às interações e das escolhas metodológicas do docente, as quais certamente influenciaram no produto.

Sendo assim, minha pesquisa de doutorado, que está em andaAtividades de ensino e interação entre pares mento desde agosto de 2017, nasceu da necessidade por mim constatada de olhar para o outro polo, ou seja, para o ensino. Dessa forma, em nível de doutorado, continuo a realizar um trabalho ligado à produção oral e à interação em início de aprendizagem, mas o foco da investigação é o professor e os instrumentos de que lança mão visando ao favorecimento dessa competência.

Sendo assim, no presente artigo, de cunho essencialmente teórico, apresento, com base em obras relacionadas à questão, as razões pelas quais um ensino que favoreça a interação entre pares pode conduzir ao desenvolvimento de competências para a comunicação em língua estrangeira. Discorrerei primeiramente sobre os dois tipos de interação que acontecem no interior da sala de aula: a interação assimétrica (professor x aluno) e a interação simétrica (entre os aprendizes), dando maior atenção a esta segunda modalidade e abordando dois aspectos a ela relacionados: a interação como ferramenta que proporciona mais aproximação entre os membros do grupo e a interação como ferramenta que conduz à apropriação de competências discursivas.

Dando ênfase às atividades didáticas e evidenciando o papel crucial que desempenham no desenvolvimento da produção oral, e tendo em vista que é por meio delas que os aprendizes são chamados a interagir e desenvolver uma determinada tarefa, dedico a segunda parte do presente artigo às atividades de ensino, as quais figuram como aliadas indispensáveis ao docente, sobretudo em contextos em que a fala em língua estrangeira está restrita ao espaço da sala de aula. 
Rita de Cássia

Gomes

\section{Favorecendo a interação simétrica em sala de aula de LE}

No espaço da sala de aula, ocorrem pelo menos dois tipos de interação diferentes: a interação didática ou de ensino (CICUREL, 2011), concretizada pelas trocas verbais efetuadas entre docente e aprendizes, as quais configuram um convite à participação e um encorajamento da fala por parte do docente, o qual incita o grupo a falar na LE, e aquela que acontece entre os aprendizes e, assim como pontua Nussbaum (1998), constitui um quadro psicossocial muito diferente da cena "sala gerenciada pelo professor". Para Nussbaum, o trabalho em grupo, entre os aprendizes, implica que os indivíduos deverão, de modo autônomo, redefinir a tarefa que lhes foi proposta e encontrar os meios de resolvê-la, ou seja, o direcionamento do agir e o próprio agir são gerenciados pelos aprendizes, que deverão colaborar e ajustar suas ações e seu discurso para realizar a atividade proposta pelo professor. A interação de tal tipo, em oposição àquela que ocorre entre professor e aprendizes, é chamada de interação simétrica.

Ainda de acordo com Nussbaum (1998), a interação simétrica se assemelha muito à conversação ordinária ${ }^{3}$, tendo em vista que não há hierarquia entre os interactantes (os indivíduos que interagem verbalmente), ao contrário do que se pode observar na interação didática ou assimétrica, guiada pelo professor, o qual determina quem toma a palavra e em que momento.

Embora o objetivo do presente artigo seja expor as razões pelas quais o trabalho docente (sobretudo na elaboração de material paradidático) deve vislumbrar a interação entre os pares como parte integrante da aprendizagem, visando ao desenvolvimento da produção oral, é necessário ressaltar que a interação assimétrica (professor $\mathrm{x}$ aluno) é essencial no âmbito da sala de aula, pois o professor tem consciência dos conhecimentos já consolidados pelo seu grupo de aprendizes, daqueles que estão em construção e de quais ferramentas lançará mão para solicitar ao grupo a mobilização de ambos. Por essa razão, o convite à participação, realizado pelo docente ao introduzir um determinado assunto em

3 A definição das características pertencentes a uma conversação ordinária foi apresentada por Sacks, Schegloff e Jefferson (2003), para os quais, em qualquer conversa: (1) a troca de falantes se repete, ou pelo menos ocorre; (2) na grande maioria dos casos, fala um de cada vez; (3) transições (de um turno para o próximo) sem intervalos e sem sobreposições são comuns (...); (4) a ordem dos turnos não é fixa, mas variável; (5) o tamanho dos turnos não é fixo, mas variável; (6) a extensão da conversa não é previamente especificada; (7) o que cada um diz não é previamente especificado; (8) a distribuição relativa dos turnos não é previamente especificada; (9) o número de participantes pode variar. SACKS, H., SCHEGLOFF, E. A., JEFFERSON, G. Sistemática elementar para a organização da tomada de turnos para a conversa. Trad. NAME, M. C. e GAGO, P. C.; Juiz de Fora: Veredas, 2003. 
LE e ao convidar seus aprendizes a falar a respeito dele, os comentários sobre um tema do cotidiano, dentre outras condutas que configuram uma interação assimétrica, são meios valiosos para encorajar a participação e tornar a fala em língua estrangeira uma prática habitual.

No entanto, existe outra modalidade de trabalho: a interação entre os aprendizes, e ela possibilita uma descentralização da interação, pois a fala circula entre o grupo de alunos, e o docente atua como um facilitador da aprendizagem, auxiliando e gerenciando os pequenos grupos, esclarecendo dúvidas, cuidando para que a atividade proposta esteja de fato sendo realizada etc. É nessa modalidade de trabalho que os aprendizes aprendem a desenvolver suas habilidades discursivas em LE.

De acordo com Schiffler (1991), qualquer indivíduo possui afinidade natural com o princípio formador de grupo. 0 autor pontua que $o$ Atividades de ensino e interação entre pares aluno precisa se sentir membro de uma comunidade, mesmo quando a instituição o restringe ao trabalho individual, e esse sentimento de não estar isolado é reforçado de forma particular quando ele é convidado a trabalhar junto de um de seus colegas. Para Schiffler, um ensino interativo se funda na interação social no grupo de aprendizagem, ou seja, sobre as relações recíprocas, determinadas pela comunicação, entre, de um lado, o professor e os aprendizes e, de outro, com os aprendizes entre si. Dessa forma, a hipótese que alicerça o ensino interativo das línguas estrangeiras, tal como é definido por Schiffler (1991), é a de que uma interação positiva é condição essencial para a eficácia do ensino, e ela pode ser influenciada positivamente por um comportamento pedagógico interativo e por formas de ensino interativas.

As chamadas formas de ensino interativas apresentadas por Schiffler (1991) seriam todas as atividades didáticas cuja realização possibilite a interação entre os aprendizes e que conduzam a uma comunicação centrada no aprendiz; que incitem a autonomia, a autodecisão ou a participação e que encorajem a cooperação por meio da responsabilidade e de um trabalho de grupo interativo. Para o autor, a interação social e as formas de ensino interativas têm efeitos sobre o comportamento do professor e sobre a disposição dos aprendizes e pode, por exemplo, dissipar conflitos de participação. Sendo assim, é importante levar em consideração a relação entre os membros do grupo e o trabalho entre pares, o qual, graças à proximidade existente entre os aprendizes, proporcionaria um ambiente mais sadio no que diz respeito aos laços afetivos no interior da sala de aula. Tais vantagens também são apontadas por Nussbaum (1998). 
Rita de Cássia

Gomes

Modificando um pouco a perspectiva sobre as contribuições do trabalho em grupo para o ensino de uma língua estrangeira, citamos mais uma vez Schiffler (1991), o qual afirma que, quando se tratar de formar a competência de comunicação, a troca com um ou mais colegas será uma modalidade de exercício necessária. Segundo ele, trabalho de equipe e trabalho de grupo permitem, com uma finalidade apropriada, intensificar as ocasiões de treinamento (de minha parte, acrescentaria de exercício da fala). Assim como Schiffler (1991), Weber (2013) também discorre acerca das propriedades de aprendizagem que possui a interação entre os aprendizes.

De acordo com Weber, a construção do discurso entre pares faz emergir mais facilmente a negociação do sentido, e ela pontua que a implicação em atividades com alto grau de interação social (o jogo, por exemplo) "constitui um fator eminentemente positivo de apropriação (grifo meu), sobretudo quando ligamos a essa atividade o caráter afetivo (...)" (WEBER, 2013, p. 261). Pekarek Doehler (2000) também considera que as interações entre os aprendizes sejam o objetivo da aprendizagem quando se tratar de favorecer o desenvolvimento da fala em língua estrangeira:

Ora, postular nesse sentido a coordenação das atividades como um componente central das capacidades de comunicação desperta nossa atenção para a importância capital não daquilo que o aprendiz é capaz de produzir sozinho, mas do que ele consegue fazer com o outro e, sobretudo, do que a situação pede que ele faça (PEKAREK DOEHLER, 2000, p. 06).

Para Pekarek Doehler (2000), conforme é possível depreender da citação acima, é necessário preparar o aprendiz para que ele possa ir além da verbalização de frases no idioma-alvo e, por meio da interação, aprenda a manter uma troca verbal coerente não apenas em termos linguísticos, mas também em consonância com o contexto em que ela ocorre. Dessa forma, as palavras de Pekarek Doehler elucidam o quão positivas são as práticas pedagógicas que permitem ao aprendiz participar de trocas verbais em língua estrangeira e aprender, na prática, a manter uma interação face a face, a qual tem como prerrogativa o trabalho conjunto dos agentes envolvidos visando ao sucesso da troca verbal em curso, o que favorece, ao mesmo tempo, não só o desenvolvi- 
mento das habilidades de expressão, mas também de compreensão oral, tendo em vista que a manutenção da coerência reside na boa interpretação (escuta) daquilo que está sendo dito, o que condiciona a elaboração do turno seguinte (produção).

Nussbaum (1998) apresenta outra contribuição do "trabalho entre pares" ao afirmar que o fato de interagirem entre si, sem a vigilância constante do professor, encoraja os aprendizes a produzir. Comentando acerca de pesquisas cujo foco era investigar as atividades dos aprendizes em trabalhos em pequenos grupos, Nussbaum afirma que os resultados mostraram que a capacidade de produção e de interação são mais intensas nessa modalidade, pois "os indivíduos em situação de pares se engajam em processos de cooperação que lhes permitem compartilhar seus conhecimentos (...)" (NUSSBAUM, 1998, p. 35).

Atividades de ensino e interação entre pares

Citando uma pesquisa em que foram comparadas atividades discursivas de um mesmo grupo de alunos em sequências guiadas pelos professores e em momentos de trabalhos em grupos, Nussbaum relata que foi constatado um aumento na produção na segunda modalidade e aponta algumas hipóteses passíveis de justificar o ocorrido: primeiramente, segundo ela, no grupo reduzido, as possibilidades de intervenção de cada indivíduo são maiores e, além disso, as relações de simetria entre participantes (determinadas pelo seu status a priori igualitário) prefiguram cenários favoráveis à participação, pois as relações de poder se modificam e, consequentemente, o tratamento da face facilita a produção da fala e de ideias gerenciadas de maneira cooperativa. Nussbaum conclui dizendo que os aprendizes têm, nesse formato de trabalho, a possibilidade de participar da estruturação do tema e da organização da interação de maneira muito mais livre.

Em consonância com o que afirmam os autores supracitados Schiffler (1991), Nussbaum (1998), Pekarek Doehler (2000) e Weber (2013) -, Kramsch (1984) pontua que, enquanto membros de um grupo, professor e aprendizes devem aperfeiçoar sua capacidade de se comunicar um com o outro em língua estrangeira, tomando parte em certas atividades de grupo, por exemplo: ler um texto e discutir a respeito de seu conteúdo, fazer exercícios estruturais, realizar jogos de papéis e jogos de simulação etc. Kramsch salienta que, em um ensino tradicional, a maior parte dessas tarefas era realizada apenas pelo professor e defende que, em uma pedagogia da interação, deve-se insistir no caráter negociativo do ensino e na criação de um consenso em que é visada a distribuição. 
Acredito, em situações como as abordadas neste artigo, que podemos falar em distribuição de turnos ou de tempo de fala, tendo em vista que, em um ensino centrado no professor, é ele quem distribui os turnos e seleciona os participantes. Na maioria das vezes, o tempo de fala do professor é muito maior nesses casos, ao passo que em um ensino em que se almeja a interação entre os aprendizes, há um maior equilíbrio entre o tempo de fala do professor e o exercício da fala por parte dos alunos.

Além do fortalecimento das relações sociais no grupo, conforme aponta Schiffler (1990), e o aumento da produção dos aprendizes graças

Rita de Cássia

Gomes à segurança que traz o status igualitário no trabalho em grupo devido à simetria na interação (NUSSBAUM, 1998), vale ressaltar que, em uma situação na qual a língua estrangeira ensinada não é falada no quotidiano, a sala de aula configura, na maioria das vezes, o único espaço onde o aprendiz poderá desenvolver suas competências discursivas em situação de interação face a face. É por essa razão que, a meu ver, são extremamente pertinentes as reflexões propostas por Kramsch (1984), Nussbaum (1998), Pekarek Doehler (2000) e Weber (2013), as quais apontam que o trabalho em grupo e a interação entre os aprendizes podem conduzir à aprendizagem da construção do discurso em língua estrangeira.

No caso do ensino de língua francesa no Brasil, por exemplo, o exercício da fala, em LE, face a face, somente será possível no espaço da sala de aula. Ainda que exista a possibilidade de se encontrar falantes de língua francesa no nosso território, essa seria para o aprendiz uma ocasião de demonstrar ou verificar o que ele é capaz de produzir em LE, e não uma situação de aprendizagem. É por esse motivo que o professor de LE deve ter como objetivo ensinar a interagir e proporcionar aos seus alunos um tempo de fala considerável durante as aulas, para que possam, de fato, aprender a se expressar no idioma-alvo.

Kramsch (1984) apresenta como sendo os princípios gerais da construção do discurso a interpretação, a expressão e a negociação do sentido, os quais apenas poderiam ser mobilizados dentro de uma troca verbal, ou seja, na interação entre dois ou mais falantes. De forma bastante similar, Weber (2013) defende que em todo trabalho relacionado à competência para se comunicar linguageiramente (CCL), a atenção está centrada primeiramente na negociação do sentido, na situação em que ele deve ser construído e nas dificuldades a ele ligadas, e aponta o sentido como sendo o "vetor de força" da socialização, comparando-o à coluna vertebral de uma estrutura óssea. Para Weber (2013), em 
um ensino cujo objetivo é o favorecimento de habilidades discursivas aos aprendizes, o que interessa é facilitar a cooperação com os outros, desenvolvendo competências múltiplas, o que permitiria "desenvolver saberes linguísticos e linguageiros, transformar o repertório de informações, controlar o jogo das interações e, sobretudo, a intercompreensão" (WEBER, 2013, p. 263).

Ora, é exatamente a concepção que se tem do que é a fala e do papel que desempenha a interação nesse processo que determina como ocorrerá o ensino de uma LE. Em uma sala de aula onde há o monopólio do tempo de fala pelo professor, a prática da oralidade pelo aluno estará condicionada a pequenas intervenções, a convite do docente. Nessa interação, em que se nota normalmente a abertura da fala feita pelo professor, que configura um pedido ou uma autorização de participaAtividades de ensino $e$ interação entre pares ção por parte do aluno, seguida por uma verbalização por parte deste último e posteriormente da verificação do professor (IRF) ${ }^{4}$, a participação do aprendiz é extremamente restrita, pois é o professor quem determina quem vai falar (heterosseleção) e por quanto tempo. Estou fazendo uma pequena digressão para reforçar que esse tipo de interação (assimétrica) restringe o gerenciamento da fala exclusivamente ao professor e não confere ao aprendiz a responsabilidade de manter uma situação de interlocução, conforme ocorre em qualquer troca verbal fora do espaço da sala de aula. Dessa maneira, as estratégias de ensino do professor devem ser aprimoradas, e sua atenção deve estar voltada para a promoção de um trabalho colaborativo entre os aprendizes, para que consigam, repito, transformar o espaço da sala de aula em um lugar onde a LE é verdadeiramente colocada em exercício. É nessa interlocução que os alunos poderão vivenciar a colaboração e co-construção do discurso, elementos-chave de qualquer troca discursiva, tal como explicita Kerbrat-Orecchioni (1990).

A relevância de citar a obra de Kerbrat-Orecchioni (1990), dedicada a explicar o funcionamento de uma interação verbal, justifica-se pela contribuição que traz o conhecimento desse processo para os profissionais do ensino. Tendo em vista que o diálogo é a manifestação verbal mais recorrente no nosso dia a dia, a sala de aula deveria favorecer essa ocorrência entre os aprendizes, na língua-alvo, e possibilitar que coloquem em prática

4 SINCLAIR, J. M.; COULTHARD, R. M. Towards an analysis of discourse: the english used by teachers and pupils. London: Oxford University Press, 1975. 
seus conhecimentos por meio da fala, o que os auxiliará em interações restritas ao espaço da sala de aula e também em situações que ocorrem fora do ambiente de aprendizagem. Assim como pontua Cicurel (2002):

Em uma situação de sala de aula, é exigido dos participantes realizar uma sequência de ações verbais, em uma certa ordem e segundo um certo método. A ocorrência de atividades didáticas distingue radicalmente a apropriação em meio guiado da aquisição em meio aberto. É o professor, mediador do processo

Rita de Cássia

Gomes

de aprendizagem, que realiza a atividade didática, que podemos definir como uma atividade linguageira que se desenvolve segundo um protocolo, proposto pelo manual ou pelo instrutor, e a qual demanda dos usuários um enorme esforço cognitivo. 0 esquema de uma atividade didática é reconhecido pelos participantes; o professor explica o funcionamento, dá legitimidade a essa atividade e expõe a maneira de realizá-la como se apresentasse as regras de um jogo (CICUREL, 2002, p. 05).

Conforme explicitado na citação acima, é o professor quem conduz a forma como se dará o ensino e é por meio das atividades didáticas que ele propõe aos aprendizes um determinado trabalho a ser realizado, o que quer dizer que as atividades funcionam como o cenário dentro do qual os alunos deverão agir, ou interagir. A atividade didática faz parte do contrato didático ${ }^{5}$ firmado entre o professor e o grupo de aprendizes e, no contexto da sala de aula, tal como aponta Cicurel (2002) no trecho supracitado, constitui um componente indispensável para a aprendizagem.

No que tange ao ensino de língua francesa, a partir da década de 1980, com as orientações da Abordagem Comunicativa, o foco do ensino passou a se direcionar para o aluno, e, tendo em vista que a prerrogativa dessa abordagem era a de que saber um idioma estrangeiro seria saber se comunicar respeitando as regras do contexto e as características dos interlocutores, tornou-se necessário lançar mão de dispositivos pedagógicos e didáticos que atendessem às necessidades dos diversos públi-

5 Toda situação de ensino/aprendizagem é regida por um contrato didático: os agentes aceitam que as ações aconteçam de tal maneira que haja um resultado, o resultado sendo uma modificação do saber dos aprendizes. Não é possível fazer uma análise das interações em sala sem se referir a esse contrato. Se o professor se utiliza de atividades pedagógicas diversas é porque julga que tais atividades possam favorecer a aprendizagem. (CICUREL, F. Les interactions dans l'enseignement des langues-Agir Professoral et pratiques de classe. Paris: Didier, 2011, p. 23). Tradução nossa. 
cos de aprendizes (MARTINEZ, 2014). Foi nesse contexto que surgiram tipos de atividades de produção oral que simulavam situações da vida quotidiana, no intuito de preparar o aluno para uma futura comunicação no idioma estrangeiro. Assim, essa abordagem conferiu importância capital ao exercício de comunicação entre os aprendizes.

Atualmente, a Perspectiva Acional, que está na base teórica do Quadro Europeu Comum de Referência para as Línguas (CECRL), em voga no ensino de língua francesa nos dias atuais, corrobora as orientações da Abordagem Comunicativa e vai um pouco além, pois não se fala mais em comunicação, e sim em interação ${ }^{6}$ e entende-se essa troca como uma prática a ser encorajada pelos docentes e formadores: "aprender a interagir supõe mais que aprender a receber e a produzir enunciados. Vemos como sendo crucial a interação no uso e na aprendizagem da língua, dado o papel central que ela desempenha na comunicação." (CONSEIL DE L'EUROPE, 2005, p. 18).

A afirmação presente no CECRL explicita que a fala constitui uma ação conjunta, a qual se constrói entre os sujeitos envolvidos na troca verbal e, por isso, a interação entre os aprendizes deve integrar o ensino de uma língua estrangeira, pois é por meio desse tipo de interação que ocorrerá o recurso às estratégias necessárias para interagir oralmente. Considerando tal premissa, o papel do professor seria, então, favorecer a participação dos aprendizes por meio da interação assimétrica e também propor atividades de ensino que visem a proporcionar a mobilização da fala em interação com os pares (simétrica), como exercício que é parte integrante da aprendizagem.

\section{O papel das atividades didáticas}

Quando se fala em interação simétrica ou interação entre pares no contexto da sala de aula, uma pergunta que vem à mente é como indivíduos que estão iniciando na língua estrangeira vão se colocar um diante do outro e falar na língua-alvo, tendo em vista a gama de restrições a que essa comunicação está sujeita.

6 Em uma concepção interacionista, a fala é concebida como sendo uma ação coletiva e situada, que se constrói entre dois ou mais indivíduos, responsáveis pela manutenção da interação. Em negação a uma vertente imanentista e monologal de análise linguística, o objeto de estudo dos interacionistas são as conversações que ocorrem entre indivíduos concretos, em situações reais. Procura-se entender como eles constroem essa teia que é a interação, os sinais utilizados para demonstrar sua implicação discursiva, identificar possíveis, lacunas, dentre outros fenômenos que ocorrem no interior da troca discursiva e que influenciam positiva ou negativamente nesse processo. Ao consultar a bibliografia do CECRL, é possível notar a forte influência da vertente interacionista na Perspectiva Acional, ou seja, a metodologia de ensino atual confere à interação um lugar privilegiado quando se fala em ensinar a agir ou interagir oralmente por meio da língua. 
Rita de Cássia

Gomes

A meu ver, as respostas passíveis de apresentar um horizonte favorável à emergência de uma interação simétrica em sala de aula de LE estão relacionadas às ferramentas das quais o docente se servirá visando a alcançar tal feito, pois ele é o único que conhece as características próprias ao contexto em que atua. Assim, é por meio de atividades didáticas, as quais estão em consonância com o nível linguístico do grupo e com os temas previstos no conteúdo programático, que o professor fará trabalhar seu grupo de alunos. Destarte, as atividades didáticas desempenham um papel crucial em um contexto onde a língua estrangeira não é falada no quotidiano, pois, assim como pontua Weber (2013), é por meio dessa ferramenta que o professor determina os quadros ou os esquemas interacionais que o aprendiz deverá mobilizar.

De acordo com Weber (2013), cada um dos esquemas propostos (as atividades) fará intervir a experiência adquirida e o que está sendo desenvolvido, e ela acrescenta que a exposição a conversações imaginárias pedagogicamente adaptadas, e que facilitem a compreensão, pode constituir um ponto de apoio precioso para o aprendiz. Em resumo, Weber pontua que "cada modelo ou quadro proposto ao aprendiz é uma ajuda ao desenvolvimento das competências para se comunicar linguageiramente" (WEBER, 2013, p. 264).

Acrescentaria, de minha parte, que é justamente no esforço de alcançar o objetivo proposto pelas atividades que o aprendiz mobilizará seus saberes e recorrerá a estratégias discursivas em LE. Ora, assim como afirma Pendanx (1998), “é por meio delas (das atividades) que ele (aprendiz) realiza as operações de tratamento de um dado material linguageiro em circunstâncias determinadas" (PENDANX, 1998, p. 61). Sendo assim, tendo em vista a particularidade da produção discursiva no espaço da sala de aula, o contexto apresentado pelas atividades desempenha um papel fundamental na interação, pois "ele condiciona as escolhas sintáticas, lexicais e discursivas realizadas pelo aprendiz" (WEBER, 2013, p. 297).

Ainda segundo Pendanx (1998), em sala de aula o professor propõe várias atividades que colocam em jogo operações específicas de tratamento linguageiro: elas podem se aproximar das atividades linguageiras "naturais" (como os jogos de papéis) ou podem ser mais características da aprendizagem institucional (como os exercícios de gramática), mas são sempre realizadas em uma situação de ensino, visando à realização de tarefas de tratamento linguageiro e à utilização 
de estratégias em um objetivo de aprendizagem. Para essa autora, as atividades de ensino, dado o trabalho que exigem do aprendiz, conduzem à aprendizagem.

Fazendo uma afirmação que se aproxima muito das palavras de Pendanx (1998), Nussbaum (1998) pontua que, quando realizam uma tarefa, os indivíduos se engajam em atividades que buscam a construção do sentido, que permitem a tomada de consciência de fenômenos linguageiros, o reconhecimento de problema, a verificação de hipóteses bem como a discussão com os parceiros, e seria essa capacidade de reestruturação ao longo do caminho que conduziria à dinâmica da aprendizagem.

As colocações das autoras Nussbaum (1998) e Pendanx (1998) a respeito das atividades didáticas evidenciam a necessidade de refletir Atividades de ensino e interação entre pares acerca desse instrumento e, por tal razão, ao proceder à elaboração de uma determinada atividade, o professor precisa ter em mente os objetivos de aprendizagem que deseja fazer alcançar, os saberes que o aprendiz precisa dominar para realizar a atividade, aqueles que estão sendo consolidados e a possível mobilização de ambos, ou seja, é preciso antecipar o trabalho a ser realizado pelo aprendiz e verificar se os seus objetivos de ensino estão afinados com as capacidades e necessidades do grupo. Esse mapeamento (ou reflexão) permite que o docente tenha maior clareza dos seus objetivos e daquilo que solicita a seus aprendizes, o que resultará em propostas de atividades didáticas mais coerentes. A esse respeito, Pendanx (1998) salienta:

\footnotetext{
Uma dada atividade de ensino/aprendizagem se deixa analisar segundo vários parâmetros, tais como: enunciado, tipo de produção esperada, suporte de partida, objetivo, conteúdos, etc. (...). Todavia, nosso objetivo sendo o de tentar elucidar o que são as aprendizagens efetivamente realizadas durante a realização das atividades (...) nós consideramos que os principais componentes dessas tarefas são aqueles que permitem dar conta da atividade efetivamente realizada pelo aprendiz: primeiramente o conteúdo de aprendizagem do qual ele vai se apropriar, em seguida o tratamento linguageiro que ele vai efetuar e finalmente o conjunto de meios que ele tem à sua disposição para conduzir satisfatoriamente esse trabalho (PENDANX, 1998, p. 65).
} 
A citação acima evidencia que o tratamento linguageiro realizado durante a troca verbal proporcionada por uma determinada atividade didática conduz à apropriação de condutas discursivas em língua estrangeira. Portanto, o trabalho do docente passa pela análise tanto da atividade didática quanto da bagagem linguageira dos aprendizes, os quais precisam estar em condições de realizar (verbalmente) a tarefa. Uma proposta de reflexão parecida pode ser encontrada em Vasseur (2005), a qual argumenta: “a questão central (...) é exatamente a articulação entre a interação verbal e o processo cognitivo que chamamos

Rita de Cássia

Gomes aquisição e que se encontra no foco dos estudos atuais" (VASSEUR, 2005, p. 284). Enriquecendo a reflexão acerca do tema, citamos as palavras de Cicurel (2002), que afirma:

\begin{abstract}
(...) a atividade didática é, sem dúvida, o vetor da apropriação. O enunciado, sob a forma de um dizer como fazer, constitui um discurso intermediário entre a atividade solicitada e sua realização pelos aprendizes parceiros. A apropriação em sala de aula passa pela efetuação dessas atividades e pela compreensão da tarefa a realizar (CICUREL, 2002, p. 05).
\end{abstract}

A citação da autora (CICUREL, 2002) aponta pelo menos três aspectos relacionados à produção oral e ao trabalho docente, ambos ligados à atividade didática. Primeiramente, ao dizer que a atividade didática é o vetor da apropriação, a autora ratifica a importância dessa ferramenta de ensino. Posteriormente, ao afirmar a necessidade da efetuação das atividades, ela explicita que o trabalho linguageiro por parte do aprendiz é indispensável, ou seja, ele precisa ter a oportunidade de colocar em prática, oralmente, aquilo que é solicitado pela atividade didática para que haja a apropriação. Finalmente, a autora afirma que a tarefa a ser realizada precisa estar clara, e o faz ao mencionar a "compreensão da tarefa a realizar". A meu ver, ela exorta os docentes para o trabalho de mapeamento, o qual mencionei anteriormente: ter ciência dos objetivos de ensino, daquilo que se deseja fazer emergir com a atividade proposta, considerando a bagagem linguística do grupo de aprendizes.

A clareza e a coerência de uma atividade de ensino que tenha o intuito de proporcionar uma melhor compreensão pelo aprendiz também são mencionadas por Weber (2013), segundo quem, o enunciado elaborado pelo formador é essencial, pois permite ao aprendiz anteci- 
par cognitivamente sua produção (isso porque, antes de falar, ele tem consciência daquilo que vai dizer e daquilo que é capaz de produzir em LE). Além disso, de acordo com Weber (2013), é importante que esteja claro para o aprendiz o uso que fará de seus conhecimentos linguísticos, os quais possibilitam a realização de uma determinada ação (objetivo linguístico-comunicativo) em língua estrangeira. Por exemplo, é necessário saber como se conjugam os verbos no passado para contar a um colega aquilo que se fez durante as férias. Tal utilidade dos conhecimentos linguísticos é denominada pela autora competência funcional, conforme se observa no trecho abaixo:

Atividades de ensino e interação entre pares

Pontualmente, podemos focar na coerência de uma atividade (ligar uma série de elementos curtos) ou sobre o uso de conectores para reforçar um ponto de vista. A atividade pode se decompor em constituintes implícitos: o aprendiz se dará conta de que não está ali simplesmente para ajustar sua fala e seu discurso, mas que a coerência está a serviço de uma competência funcional (grifo nosso). É por essa razão que é importante determinar a relação entre as características a serem tratadas e a natureza da tarefa pedida (WEBER, 2013, p. 276).

Complementando as ideias apresentadas na citação acima acerca da coerência e da objetividade das atividades de ensino, Weber (2013) pontua, em outro trecho de sua obra, que a precisão dos objetivos, a boa escolha dos recursos e a clareza do enunciado da atividade tornarão a planificação e a gestão da interação mais facilmente realizáveis pelos aprendizes. Pensar em todos esses fatores ao elaborar ou propor uma atividade didática traduz um trabalho próprio da conduta docente, o qual Cicurel (2002) denomina práticas de transmissão, as quais englobam as atividades didáticas formalizadas (como exercícios gramaticais, traduções, comentários de textos, jogos etc.) e também práticas pedagógicas mais livres, como os materiais utilizados e todas as práticas discursivas do professor visando a tornar seus aprendizes mais proficientes.

Restringindo as práticas de transmissão apontadas por Cicurel (2002) unicamente às atividades didáticas, dados os objetivos do presente artigo, ressaltarei, com base na obra de Pendanx (1998), critérios que, a meu ver, se levados em consideração, podem auxiliar na elaboração e também na aplicação de atividades de produção oral. 0 primeiro deles 
Rita de Cássia

Gomes

582

é o suporte. Segundo Pendanx (1998), trata-se de uma ajuda oferecida ao aprendiz: seja sob a forma de um documento ou suporte anexo, da ilustração de um exemplo ou de perguntas de elucidação, "o aprendiz pode ser guiado de diversas maneiras e a ajuda que é dada constitui um apoio cognitivo importante para ele" (PENDANX, 1998, p. 68).

A reflexão de Pendanx remete, por exemplo, a um aspecto prático, que seriam as fichas entregues aos aprendizes no momento da realização das atividades. Elas direcionam o discurso a ser produzido, conferindo mais tranquilidade e, ao mesmo tempo, objetividade, pois se trata de um apoio que pode apresentar os dados contextuais, as características dos locutores, as restrições da atividade etc., ou seja, ao mesmo tempo que configura uma ajuda, o suporte é uma forma de evitar que o aprendiz fuja do objetivo previsto pelo docente.

A escolha do tipo de suporte está muito relacionada à forma como o professor vai propor a realização da atividade. Segundo Pendanx (1998), a escolha de uma modalidade ou de outra (individual ou coletivamente) confere à atividade uma dimensão afetiva ou distanciada, que tem implicações diversas para o aprendiz (...). Tal reflexão aponta, a meu ver, para a necessidade de diversificar os tipos de interação e disposição de grupo, pois cada atividade, dependendo da forma como os aprendizes estão dispostos, terá uma implicação diferente e permitirá a aprendizagem de um determinado tipo de discurso e a familiarização com situações de interação diversificadas.

Outro aspecto apontado por Pendanx (1998) no que diz respeito à elaboração ou proposta de atividade didática é o tempo investido. Essa restrição deve ser levada em consideração em uma situação de ensino/ aprendizagem, pois ao elaborar uma determinada atividade o professor imagina o tempo que os aprendizes levarão para realizá-la, o que de fato é um fator relevante no que tange ao gerenciamento do grupo, pois, se o tempo for muito curto, os aprendizes podem não conseguir realizar os objetivos propostos pela atividade, e, se for muito longo, o trabalho tende a se tornar entediante.

Pendanx (1998) menciona outro aspecto, o qual está relacionado à forma como o professor propõe que as atividades de produção oral sejam realizadas: de forma improvisada ou previamente preparada? Para Pendanx, a improvisação ou a reflexão do aprendiz influenciam suas produções e fazem parte dos critérios de avaliação do domínio de uma língua estrangeira. Enquanto pesquisadora, vejo a sala de aula como lugar favo- 
rável ao desenvolvimento e, por essa razão, creio que a não preparação prévia do discurso traga contribuições para a aprendizagem que vão além da possibilidade de avaliar o domínio que o aprendiz possui da língua estrangeira. Essa forma de construir o discurso permite que o aprendiz aprenda a, de fato, manipular as estratégias necessárias para se expressar na língua-alvo. Tendo em vista que a imprevisibilidade está presente em qualquer situação de interação face a face, ao propor atividades que dão origem a interações improvisadas, como, por exemplo, os jogos de papéis, o professor está oferecendo ao seu grupo a oportunidade de vivenciar a participação em uma troca verbal que tem um objetivo específico e cujo sucesso depende de sua performance (linguageira).

Luzzati (2013) afirma que “(...) pretender ensinar um oral espontâneo é um contrassenso e que poderíamos, no máximo, favorecer sua Atividades de ensino e interação entre pares emergência (...)" (LUZZATI, 2013, p. 199), mas, conforme atenua o autor, "se não é possível ensinar o oral espontâneo, é possível encontrar uma via para integrá-lo (...)" (LUZZATI, 2013, p. 202). Para mim, a tarefa do professor consiste justamente na tentativa de encontrar tal via, a qual, acredito, poderia ser construída por atividades de ensino que coloquem os aprendizes em uma situação de interação verbal que conduzam à familiarização com o exercício da coprodução e da interlocução, característica das trocas verbais espontâneas (KERBRAT-ORECCHIONI, 1990). Todavia, considero que o produto é menos significativo que o processo, e, por isso, estou de acordo com as afirmações de Bange (1996):

\footnotetext{
(...) o que conta para a aprendizagem não é o resultado correto (por exemplo, a conformidade do enunciado obtido com a norma da língua-alvo), mas o trabalho cognitivo ao qual o aprendiz é incitado no objetivo de modificar um comportamento e certas circunstâncias. Apoiar a aprendizagem é abrir um caminho e não impor um resultado, abrir um caminho no qual o aprendiz avançará tanto bem quanto mal; é implicar o aprendiz na realização da tarefa (BANGE, 1996, p. 05).
}

O lugar a ser ocupado pelo aluno na sala de aula é objeto de discussão e gera reflexões de diversas ordens há bastante tempo. $\mathrm{O}$ objetivo do presente artigo foi propor reflexões acerca desse lugar, mas também, e sobretudo, no que diz respeito às ações do professor, ou seja, sobre como colocar o aluno no centro da aprendizagem, no tocante es- 
Rita de Cássia

Gomes

pecificamente ao favorecimento da produção oral. Sendo assim, busquei apresentar uma forma de conceber o ensino de língua estrangeira e a elaboração de atividades de produção oral que possibilitem a descentralização do tempo de fala e a valorização da interação entre os aprendizes por meio de atividades didáticas.

Quando se fala em descentralizar o ensino, colocando o aluno no centro da aprendizagem, é imprescindível considerar as formas de fazê-lo, e, nesse contexto (sala de aula), são as escolhas didático-metodológicas do docente que darão o tom, pois é ele quem seleciona ou elabora as atividades e gerencia a aprendizagem de seu grupo. Ainda que guiado por um livro didático, é o docente quem escolhe as ferramentas de ensino e seleciona aquelas que atendam de maneira mais satisfatória às necessidades do seu público. Portanto, o presente artigo teve como público-alvo os colegas, professores de língua estrangeira, que procuram proporcionar aos seus aprendizes um tempo de fala mais significativo.

A imagem que tenho da sala de aula em uma perspectiva interacionista é a de uma orquestra, onde o professor é o mestre que rege o espetáculo, mas cuja voz não se ouve, ou se ouve muito pouco. A voz é dada ao seu grupo, aos aprendizes. Em tempos de metodologias que incentivam uma postura mais ativa por parte do aprendiz, pensar em como favorecer tal postura no que tange à fala em língua estrangeira se torna, a meu ver, tanto coerente quanto necessário.

\section{REFERÊNCIAS:}

BANGE, P. "Considérations sur le rôle de l'interaction dans l'acquisition d'une langue étrangère”. In : Les Carnets du Cediscor. Disponível em: http://cediscor.revues.org/443. Acesso em: 03 jun. 2016.

CICUREL, F. La classe de langue un lieu ordinaire, une interaction complexe. AILE. n. 16, pp.145-164, 2002.

Les interactions dans l'enseignement des langues. Paris: Didier, 2011.

CONSEIL DE L'EUROPE. Cadre éuropéen commun de référence pour les langues. Paris: Didier, 2005. 
GOMES, Rita de Cássia. Interações verbais: analisando práticas centradas na espontaneidade e na solução de problemas em nível inicial de FLE. São Paulo, 2012. Dissertação (Mestrado em Letras). Universidade de São Paulo, Departamento de Letras Modernas, Programa de Estudos Linguísticos, Literários e Tradutológicos em Francês.

KERBRAT- ORECCHIONI, C.K. Les interactions verbales. Paris: Atividades Armand Colin, 1990.

de ensino e interação

KRAMSCH, C. Interaction et discours dans la classe de langue. entre pares

Paris: Hatier, 1984.

LUZZATI, D. “Enseigner l'oral spontané”. In: BEACCO, Jean-Claude. Éthique et politique en didactique des langues - Autour de lanotion de responsabilité. Paris: Éditions Didier, 2013.

MARTINEZ, P. La Didactique des Langues Étrangères. Paris : Presses Universitaires de France, 2014.

NUSSBAUM, L. "Émergence de la conscience langagière en travail de groupe entre apprenants de langue étrangère". In: Langages, $33^{\mathrm{e}}$ année, n. 134, 1999. Interaction et langue étrangère, sous la direction de Jo Arditty et Marie-Thérèse Vasseur. pp. 35-50.

PEKAREK-DOEHLER, S. (2000). “Approches interactionnistes de l'acquisition des langues étrangères: concepts, recherches, perspectives". In: Aile-Acquisition et interaction en Langue Étrangère, no 12, Association Encrages, pp. 03-26. Disponível em: http://aile. revues.org/934. Acesso em: 22 mai. 2016.

PENDANX, M. Les activités d'apprentissage en classe de langue. Paris: Hachette, 1998.

SACKS, H., SCHEGLOFF, E. A., JEFFERSON, G. Sistemática elementar para a organização da tomada de turnos para a conversa. Trad. NAME, M. C. e GAGO, P. C.; Juiz de Fora: Veredas, 2003. 
SINCLAIR, J. M.; COULTHARD, R. M. Towards an analysis of discourse: the english used by teachers and pupils. London: Oxford University Press, 1975.

VASSEUR, M.T. "Peut-on localiser l'appropriation de la langue seconde? Le cas de la CLIN". In: HALTÉ, J-F, RISPAIL, M. L'oral dans la classe. Paris: L'Harmattan, 2005.

WEBER, C. Pour une didactique de l'oralité - enseigner le français Rita de Cássia tel qu'il est parlé. Paris: Didier, 2013.

Gomes 